\title{
EFEKTIVITAS LAYANAN KONSELING KELOMPOK TEKNIK SELF- MANAGEMENT UNTUK MEREDUKSI PERILAKU PROKRASTINASI AKADEMIK SISWA KELAS X SMAN 15 SURABAYA
}

\author{
Apolinarius Dari Saka \\ ${ }^{1}$ Bimbingan dan Konseling, Universitas PGRI Adi Buana Surabaya, Surabaya, Indonesia \\ *Email: apollsaka@gmail.com \\ Aniek Wirastania \\ ${ }^{2}$ Bimbingan dan Konseling, Universitas PGRI Adi Buana Surabaya, Surabaya, Indonesia \\ *Email: aniek@unipasby.ac.id
}

\begin{abstract}
Abstrak
Penelitian ini bertujuan mengukur efektivitas layanan konseling kelompok dengan menggunakan teknik self-management untuk mereduksi perilaku prokrastinasi akademik siswa kelas X SMAN 15 Surabaya. Rancangan penelitian menggunakan desain One Group Pretest Post-Test yang diberikan terhadap 6 orang siswa yang mendapatkan skor pengukuran perilaku prokrastinasi akademik pada klasifikasi paling tinggi. Instrumen yang digunakan pada penelitian menggunakan skala pengukuran. Proses penentuan sampel menerapkan teknik purposive sampling. Analisis data yang digunakan dalam penelitian ini adalah uji wilcoxon yang merupakan analisis non-parametrik menggunakan bantuan SPSS for Windows 26.0. Hasil interprestasi data statistik dalam uji wilcoxon diperoleh signifikasi sebesar 0,028. Nilai asymp.Sig (2-tailed) sebesar 0,028 lebih kecil dari 0,05 sehingga disimpulkan hipotesisnya diterima. Hasil penelitian menyimpulkan bahwa teknik self-management secara siginifikan efektif untuk mereduksi perilaku prokrastinasi akademik siswa kelas X SMAN 15 Surabaya. Kontribusi penelitian ini bagi BK adalah menambah wawasan dan ilmu bahwa teknik self-management adalah salah satu metode yang tepat dalam menyelesaikan permasalahan mengenai prokrastinasi akademik..
\end{abstract}

Kata Kunci: Prokrastinasi Akademik, Self Management, Konseling kelompok

Abstact
This study aims to measure the effectiveness of group counseling services by using
self-management techniques to reduce academic procrastination behavior in class
X SMAN 15 Surabaya. The research design used the One Group Pretest Post-Test
design which was given to 6 students who scored the highest classification of
academic procrastination behavior. The instrument used in the study used a
measurement scale. The process of determining the sample applies purposive
sampling technique. Analysis of the data used in this study is the Wilcoxon test
which is a non-parametric analysis using SPSS for Windows 26.0 . The results of
statistical data interpretation in the Wilcoxon test obtained a significance of 0.028 .
The asymp.Sig (2-tailed) value of 0.028 is smaller than 0.05 so that it can be
concluded that the hypothesis is accepted. The results of the study concluded that
self-management techniques were significantly effective in reducing academic
procrastination behavior in class X SMAN 15 Surabaya. The contribution of this


research for $\mathrm{BK}$ is to add insight and knowledge that self-management techniques are one of the right methods in solving problems regarding academic procrastination.

Keywords: Academic Procrastination, Self-Management, Group Counseling

\section{PENDAHULUAN}

Prokrastinasi akademik didefenisikan sebagai bentuk dari kondisi perilaku seseorang yang sering melakukan penundaan dalam mengerjakan tugas akademik (Ghufron, 2017). Pola perilaku individu yang sering kali melakukan penundaan terhadap tugas-tugas yang di embannya dalam kehidupan sehari-hari khususnya dunia pendidikan di era modern, dalam masyarakat sosial dipandang sebagai sesuatu problematika yang serius yang perlu diatasi. Kondisi perilaku prokrastinasi akademik merupakan suatu pola perilaku negatif yang telah berlangsung dalam periode waktu yang sangat lama dengan rentang waktu hingga tiga ribu tahun yang lalu berdasarkan sebuah penelitian (Sepehrian, 2012). Perilaku prokrastinasi akademik memiliki keterkaitan erat terhadap menurunya prestasi akademik siswa yang didasarkan pada beberapa rangkaian penelitian dari Steel (2007) tentang perilaku penundan terhadap tugas-tugas akademik yang dilaksanakan dalam sebuah perguruan tinggi di Kanada.

Siswa sering mengalami kendala dalam menyelesaikan tanggung jawab yang diberikan sesuai tenggang waktu yang ditentukan, tidak terbiasa untuk tepat waktu, menghabiskan waktu untuk persiapan yang berlebihan dan berakibat gagalnya menuntaskan tugas dengan tepat waktu. Pola perilaku yang tidak memanfaatkan waktu dengan efektif dan efesien dalam menyelesaikan suatu tugas yang mengakibatkan terjadinya efek negatif disebut juga sebagai prokrastinasi (Ghufron, 2011). Tingkat prokrastinasi akademik saat ini berada pada kategori yang cukup tinggi Menurut hasil penelitian tentang Tingkat Prokrastinasi Akademik Siswa SMP Muhammadiyah 9 Yogyakarta oleh Munarwaroh, menunjukan bahwa tingkat prokrastinasi akademik berada pada level yang cukup tinggi berdasarkan besaran persentase dari hasil penelitian yang jabarkan yakni hanya 5,7 \% siswa yang memiliki perilaku prokrastinasi akademik dalam kategori rendah (Munarwaroh, 2017).

Solomon \& Rothblum (Ramadhani, 2016) memaparkan definisi yang hampir sama mengenai prokrastinasi akademik yaitu sebuah tendensi perilaku yang melalaikan tugas yang diberikan dengan mendahulukan aktifitas lain yang tidak penting sehingga mengakibatkan tertundanya tugas utama yang harus kerjakan tepat waktu. Brown \& Holzman (Febriani, 2017), 
mengatakan bahwa prokrastinasi menunjukan pada suatu kecenderungan menunda-nunda pekerjaan. Menurut Ferrari (Nursalim, 2018) prokrastinasi adalah suatu bentuk tindakan yang tidak didasarkan pada sebuah pemikiran dengan pertimbangan yang matang dengan tendensi putusan yang dibuat tidak sesuai dengan keyakinan hatinya.

Perilaku prokrastinasi akademik yang sering dibuat siswa adalah efeek dari suatu keyakinann yang irasional. Timbulnya perilaku prokrastinasi menurut Schraw (Munarwaroh, 2017) berawal dari pola pikir yang menyimpang, seperti: "nanti juga masih sempat waktunya buat dikerjakan" atau "ahh masih banyak waktu, saya dapat menyelesaikannya nanti". Permasalahan berpikir keliru berawal dari pembelajaran yang diterima dengan tidak benar yang sering diperoleh dari faktor genetik orang tua atau kultur dimana individu di didik. Siswa seringkali merasa takut ketika dihadapkan pada sebuah tugas dan menganggap tugas tersebut adalah beban yang berat yang tidak mampu diselesaikan. Faktor lain yang mengakibatkan timbulnya perilaku prokrastinasi akademik diantaranya adalah prioritas yang kurang dari siswa, keinginan untuk cenderung mendapat kesenangan sementara kurang pengelolaan diri, dan manajemen waktu yang rendah.

Menurut Steel (Munarwaroh, 2017) siswa yang terbiasa menunda tugas akademik biasanya sering memperoleh nilai yang kurang bagus pada setiap mata pelajaran ataupun ujian. Perilaku prokrastinasi akademik memiliki konsekuensi yang negatif dan berpengaruh secara nyata terhadap pribadi siswa, misalnya skor akademik siswa berada dibawah rata-rata, kesulitan untuk menempuh pendidikan kejenjang berikutnya, memiliki jumlah absensi yang tinggi, dan dampak yang paling buruk adalah diberhentikan dari sekolah. Dukungan dan perhatian yang rendah oleh orang tua sebagai akibat dari kurangnya kontrol dan pengawasan menjadi alasan perilaku ini muncul pada siswa.

Bimbingan dan konseling sebagai bagian penting dari sekolah perlu memiliki peranan aktif untuk membantu mengentaskan persoalan yang sedang dihadapi oleh para siswa. Prokrastinasi sebagai salah satu masalah dalam lingkungan pendidikan formal perlu mendapat penanganan dan perhatian lebih. Layanan dalam bimbingan dan konseling perlu memberikan sebuah perlakuan khusus dengan menggunakan teknik yang tepat sehingga diharapkan mampu membimbing siswa supaya dapat mereduksi perilaku prokrastinasi akademik yang dialami oleh siswa. Siswa yang cenderung berperilaku prokrastinasi apabila tidak segera diatasi maka dapat mempengaruhi tingkatan prestasi belajar siswa yang tentunya akan semakin rendah, sehingga mengakibatkan siswa tidak dapat mencapai tingkatan pengembangan kemampuan akademik, 
Efektivitas Layanan Konseling Kelompok Teknik Self-Management Untuk Mereduksi Perilaku Prokrastinasi

dan beerkahir dengan kegagalan siswa untuk naik kelas. Guru bimbingan dan konseling harus memaksimalkan skill yang dimiliki agar siswa tidak mengalami prokrastinasi akademik melalui perannya untuk membantu menumbuhkan sikap bertanggung jawab pada siswa dalam menyelesaikan kewajiban akademiknya

Prokrastinasi akademik berkaitan dengan kelakuan (behaviour) yang mempengaruhi kepribadian siswa, sehingga harus mempunyai self-management yang baik agar dirinya mampu mereduksi perilaku negatif tersebut. Teknik yang sesuai dengan masalah perilaku menunda-nunda tugas dalam pendekatan behavior adalah memakai layanan konseling kelompok teknik self-management. Layanan konseling kelompok dengan teknik selfmanagement, diharapkan mampu mereduksi tingkat perilaku prokrastinasi akademik siswa.

Teknik self-management sangat dibutuhkan dalam pengelolaan seluruh daya dan kapabilitas siswa. Teknik self-management adalah rangkaian metode tertentu yang harus dijalankan individu agar dapat mengatur dan menyusun perilaku yang dimiliki. Menurut Komalasari (Yospina, 2019) pada teknik self-management, siswa ikut andil dalam sebagian atau semua unsur pokok dalam prosedur teknik ini diantaranya menetapkan tujuan tingkah laku yang diinginkan, mengawasi tingkah laku tersebut, menetapkan tahapan yang akan diimplementasikan, melaksanakan tata cara prosedural tersebut, dan melaksanakan asesmen terhadap kefektifan rangkaian prosedural tersebut. Teknik self-management bisa dimanfaatkan oleh siswa agar dapat mengawasi dirinya sendiri dimulai dari aspek emosi dan tingkah laku serta dapat mengontrol rangsangan lain pada dirinya.

Menurut Sukadji (Komalasari, 2017) self-management dideskripsikan sebagai susatu langkah yang diambil oleh siswa dalam mengarahkan setiap tingkah laku yang dimiliki. Permasalahan yang dapat diselesaikan dengan self-management diantaranya pada perilaku negatif yang berkaitan dengan diri siswa tetapi mengganggu sekitarnya bahkan dirinya sendiri. Perilaku tersebut muncul tiba-tiba karena beragam faktor dan tidak mampu dikontrol sehingga pengawasan orang lain disekitarnya menjadi tidak maksimal. Pendapat lain juga disamapaikan The Liang Gie (Ulfa, 2018) bahwa manajemen diri berarti mendorong siswa untuk maju, mengelola semua komponen kamampuan siswa, mengontrol potensi diri siswa untuk mencapai perilaku yang positif, dan menumbuhkan beragam unsur dari diri siswa sehingga menjadi lebih berkembang. Siswa lebih menginginkan penguatan (reinfocement) terhadap kesenangan sesaat yang lebih menarik sehingga memunculkan perilaku prokrastinasi seperti mengutamakan aktivitas yang kurang penting daripada melaksanakan kewajiban utamanya. 
Peneliti mengharapkan penggunaan teknik self-management memiliki dampak yang signifikan dalam mereduksi perilaku prokrastinasi akademik pada siswa. Teknik selfmanagement berperan untuk memperbaiki tingkah laku yang kurang baik menjadi lebih baik melalui proses belajar perilaku yang berbeda dan baru. Prosesnya dilaksanakan dengan cara mengasah kemampuan pikiran dan dan tindakan yang diambil untuk diarahkan menjadi lebih baik sehingga membantu siswa memperoleh kemampuan dalam memanajemen waktu. Teknik penting yang digunakan oleh peneliti adalah: positive reinforcement, precious card, conformation, behaviour contract, characterization, self-management, elimination, saturation, punishment, dan disentisasi sistematis.

Tingkat prokrastinasi yang masih terjadi hingga saat ini perlu dikaji untuk mendapatkan solusi penanganan dengan menggunakan cara dan teknik yang tepat salah satunya adalah menggunakan teknik self-management. Penelitian ini memiliki tujuan agar dapat mengetahui signifikasi efektivitas layanan konseling kelompok teknik self-management untuk mereduksi perilaku prokrastinasi akademik siswa kelas X SMAN 15 Surabaya. Berdasarkan pemaparan diatas, penulis memilih untuk mengambil judul kajian ilmiah tentang "Efektivitas layanan konseling kelompok teknik self-management untuk mereduksi perilaku prokrastinasi akademik siswa kelas X SMAN 15 Surabaya..

\section{METODE}

Proses penelitian ini dilakukan dengan metode pre-ekperimental disign menggunakan desain One-grup Pre-test \& Post-test (Suryabrata, 2003). Rancangan penelitian dilaksanakan dengan tahapan pre-test (perlakuan pra-treatment) dan post-test (perlakuan pasca-treatment): T1 adalah bentuk alat ukur pra-treatment (pre-test), T2 adalah bentuk alat ukur pasca-treatment, $\mathrm{X}$ adalah bentuk perlakuan layanan konseling kelompok dengan teknik self-management untuk mengukur tingkat prokrastinasi akademik siswa. Populasi dalam penelitian adalah siswa kelas X SMAN 15 Surabaya, dan sampel yang digunakan adalah 6 orang siswa yang memiliki tingkat prokrastinasi akademik paling tinggi. Proses penentuan sampel menerapkan teknik purposive sampling. Penentuan dan pemilihan sampel penelitian ini diperoleh dari sebaran skala pengukuran yang sudah diberikan terlebih dahulu sesuai kriteria yang dibutuhkan. Instrumen penelitian menggunakan skala pengukuran tentang tingkat prokrastinasi siswa yang digunakan harus diuji tingkatan validitas dan realibilitasnya agar dapat memperoleh data penelitian yang valid dan reliable. Valid dan reliable pada instrument penelitian berarti alat ukur dalam penelitian ini sesuai untuk tetap konsisten dan terukur dalam mengukur objek yang hendak 
Efektivitas Layanan Konseling Kelompok Teknik Self-Management Untuk Mereduksi Perilaku Prokrastinasi

diteliti. Analisis data dalam penelitian ini menggunakan uji wilcoxon dengan bantuan aplikasi SPSS for Windows 26.0.

\section{HASIL PENELITIAN DAN PEMBAHASAN}

\section{Hasil Penelitian}

Berdasarkan hasil pengukuran yang dilaksanakan pada 6 siswa kelompok eksperimen SMAN 15 Surabaya ditemukan bahwa adanya afiliasi antara teori yang digunakan dengan hasil penelitian. Pelaksanaan penelitian ini didahului dengan pelaksanaan pre-test untuk dapat menemukan subjek penelitian yang tepat. Hasil pra treatment menggunakan skala pengukuran, diperoleh 6 orang siswa yang yang memiliki prokrastinasi akademik dengan kategori tinggi. Rentang skor yang digunakan untuk mengukur tingkatan prokrastinasi akademik siswa adalah: 140-105 untuk kategori tinggi, 104-70 kategori untuk sedang, dan 69-35 untuk kategori rendah.

Grafik 1. Hasil Pre-test Prokrastinasi Akademik siswa kelas X

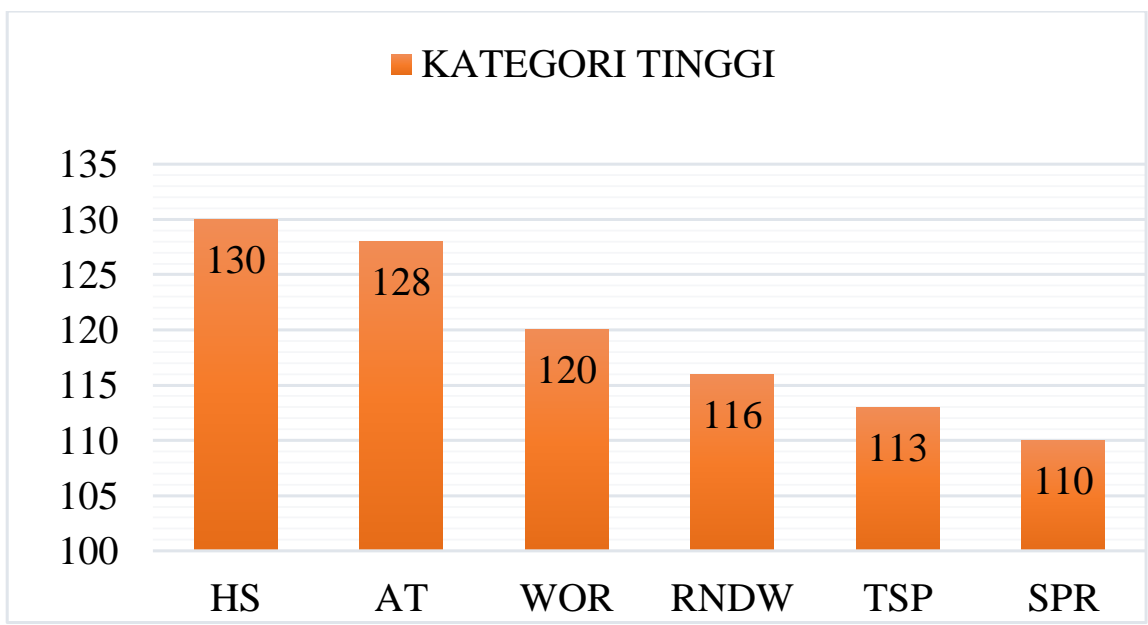

Grafik 1. diatas menunjukan bahwa hasil pre-test dengan kategori prokrastinasi akademik paling tinggi yang diperoleh sebelum siswa subjek penelitian diberikan treatment. Hasil pre-test yang dilakukan menggunakan skala pengukuran ditemukan sejumlah siswa yang mempunyai tingkatan kategori prokrastinasi akademik yang tinggi. Siswa dengan tingkat prokrastinasi akademik dalam golongan tinggi dijadikan subjek penelitian dan kemudian diberikan layanan konseling kelompok.

Subjek penelitian kemudian diberikan treatment sebanyak 6 kali secara daring melalui aplikasi google meet menggunakan layanan konseling kelompok dengan teknik selfmanagement yang bertujuan mereduksi perilaku prokrastinasi akademik. 
Grafik 2. Hasil Skor Post-test Prokrastinasi akademik siswa kelas X

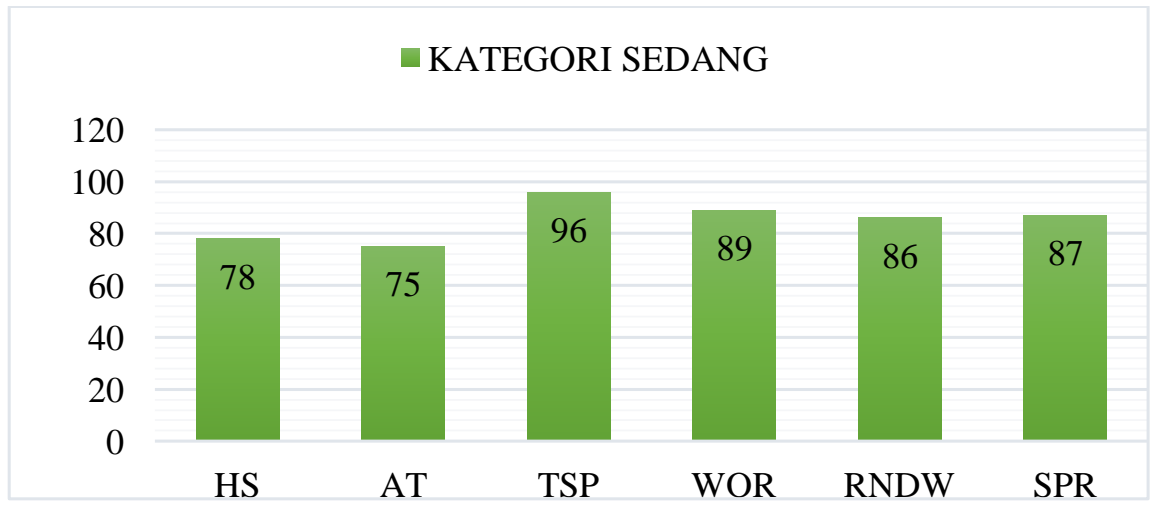

Grafik 2. menunjukan hasil perolehan skor dan kategori siswa subjek penelitian setelah diberikan 6 kali treatment. Berdasarkan perolehan hasil pada grafik diatas maka dapat dilihat adanya perubahan skor dan kategori prokrastinasi akademik siswa setelah dilakukan treatment tersebut. Siswa yang diberikan treatment tersebut mengalami perubahan berupa penyusutan tingkat prokrastinasi akademik dari kategori tinggi menuju kategori sedang.

Grafik 3. Perbandingan nilai pre-test dan post-test

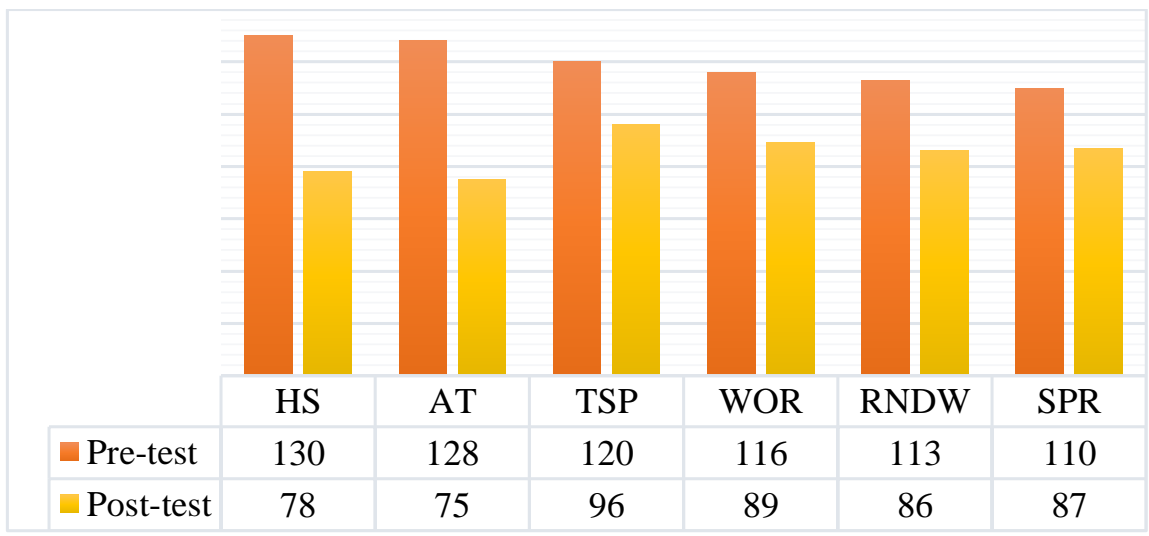

Grafik diatas menunjukan bahwa perilaku prokrastinasi akademik setiap siswa yang mendapatkan treatment telah mengalami penurunan perilaku prokrastinasi akademik. Siswa HS dan AT yang sebelumnya mempunyai tingkat prokrastinasi akademik paling tinggi mengalami penurunan paling besar diantara siswa lainnya. Siswa lainnya yakni TSP, WOR, RNDW, dan SPR juga mengalami penurunan peerilaku prokrastinasi akademik yang hampir sama. 
Tabel 1 Hasil uji wilcoxon perilaku prokrastinasi akademik siswa kelas X

\begin{tabular}{|ll|cc|c|}
\hline & & N & Mean Rank & Sum of Ranks \\
\hline Post-test - Pre-test & Negative Ranks & $6^{\mathrm{a}}$ & 3,50 & 21,00 \\
& Positive Ranks & $0^{\mathrm{b}}$ &, 00 &, 00 \\
& Ties & $0^{\mathrm{c}}$ & & \\
& Total & & & \\
\hline
\end{tabular}

\section{Test Statistics ${ }^{b}$}

\begin{tabular}{ll} 
& $\begin{array}{c}\text { Post-test } \\
\text { Pre-test }\end{array}$ \\
\hline $\mathrm{Z}$ & $-2,201^{\mathrm{b}}$ \\
\hline asymp. Sig. (2-tailed) &, 028 \\
\hline
\end{tabular}

Negative rank (peringkat negatif) adalah selisih negatif yang menunjukan adanya perubahan skor negatif sebelum dilakukan test dan setelah dilakukan tes. Berdasarkan data diatas terdapat 6 data negatif $(\mathrm{N})$ yang berarti adanya perubahan perilaku prokrastinasi akademik dari nilai pre-test ke post-test dengan jumlah 6. Mean rank menunujukan bahwa ratarata perubahan peringkat sebesar 3,50. Sum of rank atau jumlah keseluruhan peringkat sebesar 21,00. Jadi dalam penelitian ini ada penurunan perilaku prokrastinasi akademik.

Positif Rank (Peringkat Positif) adalah selisih positif yang menunjukan adanya perubahan skor positif pre-test ke post-test. Berdasarkan data pada tabel 1.6 diatas terlihat semuanya menunjukan angka 0 sehingga tidak ada perubahan angka yang ditemukan. Hal ini berarti tidak ada peningkatan perilaku prokrastinasi akademik pada siswa setelah dilakukan post-test.

Ties adalah nilai yang menunjukan kesamaan angka antara pre-test dan post-test. Data pada tabel 1.1 menunjukan bahwa nilai 0 artinya bahwa tidak ditemukan kesamaan angka antara pre-test dan post-test.

\section{Pembahasan}

Hasil interprestasi berdasarkan data test statistik menunjukkan bahwa asymp. Sig (2etaileed) memiliki nilai sebesar 0,028. Nilai angka tersebut lebih kecil dari 0,05. Berdasarkan data tersebut maka disimpulkan bahwa $\mathrm{H} 0$ diterima artinya layanan konseling kelompok teknik self-management secara signifikan efektif dalam mereduksi perilaku prokrastinasi akademik siswa kelas X SMAN 15 Surabaya. Hasil pemaparan dalam penelitian ini bahwa teknik selfmanagement efektif dalam mereduksi perilaku akademik siswa, sejalan dengan hasil 
Efektivitas Layanan Konseling Kelompok Teknik Self-Management Untuk Mereduksi Perilaku Prokrastinasi

penelitian yang dilakukan oleh Yospina (2019) tentang efektivitas konseling kelompok dengan teknik self-management untuk mengurangi perilaku prokrastinasi akademik siswa di SMA Negeri 3 Tarakan yang menyatakan bahwa teknik self-management efektif untuk mengurangi perilaku prokrastinasi akademik siswa SMA Negeri 3 Tarakan. Perbedaann penelitian ini dengan penelitian Yospina (2019) yang berjudul evektivitas konseling kelompok dengan teknik self-management untuk mengurangi perilaku prokrastinasi akademik siswa di SMA Negeri 3 Tarakan adalah analisis untuk melihat efektifvitas dari konseling kelompok dengan teknik selfmanagement menggunakan analisis data dengan uji anava campuran. Sedangkan penelitian ini menggunakan jenis penelitian dengan desain one group pre-test dan post-test design hasil analisis uji wilcoxon menunjukkan bahwa teknik self-management efektif untuk mereduksi perilaku prokrastinasi akademik siswa kelas X SMAN 15 Surabaya.

\section{KESIMPULAN}

Berdasarkan hasil penelitian yang telah dilaksanakan maka dapat ditarik kesimpulan bahwa layanan konseling kelompok teknik self-management efektif dalam mereduksi perilaku prokrastinasi akademik siswa. Siswa kelompok eksperimen mengalami penurunan perilaku prokrastinasi akademik setelah diberikan treatment dalam konseling kelompok menggunakan teknik self-management. Hal ini berdasarkan perubahan hasil skor sebelum diberikan treatment (pret-test) dan setelah diberikan treatment (post-test) yang mengalami penurunan. Hasil interprestasi berdasarkan data tes statistik menunjukkan bahwa asymp. Sig (2e-taileed) memiliki nilai sebesar 0,028. Nilai angka tersebut lebih kecil daeri 0,05. Penelitian ini berkontribusi bagi BK untuk menambah wawasan dan ilmu bahwa teknik self-management adalah salah satu metode yang tepat dalam menyelesaikan permasalahan mengenai prokrastinasi akademik.

\section{DAFTAR PUSTAKA}

Cinthia, R. 2017. Hubungan antara Konformitas dengan Prokrastinasi Akademik pada Mahasiswa. Jurnal Empati, vol. 6, 31-37

Febriani, R. 2017. Konseling Kelompok Behavioral dengan Teknik Asertif untuk Mengatasi Perilaku Prokrastinasi Akademik Siswa MTs Negri 1 Kendari. Jurnal BENING, vol. 1(2), 86-101

Ghufron, M. 2014. Teori Teori Psikologi. Yogyakarta: Ar.Ruz Media

Komalasari. 2017. Teori dan Teknik Konseling. Jakarta: PT. Indeks 
Munarwaroh. 2017. Tingkat Prokrastinasi Akademik Siswa Sekolah Menengah Pertama Muhammadiyah 9 Yogyakarta. Jurnal Kajian Bimbingan dan Konseling, vol 2(1), 26

Nursalim. 2018. Layanan Konseling Kelompok Strategi Self-Management untuk Meningkatkan Kontrool Diri Terhadap Kedisiplinan Siswa Kelas XI SMA Negeri 11 Surabya. Jurnal Bimbingan dan Konseling UNESA, vol. 1(1)

Ramadhan. 2016. Prokrastinasi Akademik Menurunkan Prestasi Belajar siswa. Jurnal Pendidikan Manajemen Perkantoran, vol. 1(1), 154-159

Sepehrian. 2012. Academic Procastination and its Predective Factors. Journal of Psycological Studies, vol. 7(4), 9-26

Steel. 2007. The Nature of Procastination: A Meta-analytic and Theoeritical Riview of Quintessential Self-Regulary Failure. Psycological Bulletin, vol 133 (1), 65-94

Ulfa. M. 2018. Efektivitas Layanan Konseling Kelompok melallui Teknik Self-Management untuk Meningktkan Kebiasaan Belajar Siswa Kelas VIII SMPN 1 Kapontori. Jurnal Psikologi Konseling, vol. 12, 120-132

Yospina. 2019. Efektivitas Konseling Kelompok dengan teknik Self-Management untuk Mengurangi Prilaku Prokrastinasi Akademik Siswa di SMA Negeri 3 Tarakan. Jurnal Bimbingan dan Konseling Borneo, vol 1(1), 1-7 